\section{New mechanism for sulfonylureas}

\section{By Lauren Martz, Staff Writer}

Japanese researchers have uncovered a second mechanism by which sulfonylureas stimulate insulin production. ${ }^{1}$ Exploiting the new mechanism to develop sulfonylurea analogs could produce compounds that do not exhaust the insulin-producing capacity of pancreatic $\beta$ cells. The question is whether such compounds could generate better results than marketed incretin analogs and receptor agonists that work upstream in the pathway.

Sulfonylureas are the oldest class of oral diabetic drugs. The first sulfonylurea was approved in the U.S. in 1954. The drugs block the ATP potassium channel $\left(\mathrm{K}_{\mathrm{ATP}}\right)$ on pancreatic $\beta$ cells, thus causing membrane depolarization and the release of insulin. In healthy patients, higher glucose levels are sufficient to alter the membrane potential of pancreatic $\beta$ cells and stimulate insulin secretion, but the process is impaired in type 2 diabetics.

However, the problem with sulfonylureas is that direct interaction with the potassium channel causes insulin resistance.

"Sulfonylureas are active at the $\mathrm{K}_{\text {ATP }}$ channel and cause persistent depolarization of $\beta$ cells and release of insulin, even in the absence of glucose," said Gregory Hockerman, associate professor of medicinal chemistry and molecular pharmacology at Purdue University. "This leads to an increased risk of hypoglycemia and may contribute to $\beta$ cell burnout, a phenomenon whereby type 2 diabetics generally lose their ability to secrete insulin."

In a paper in Science, a team at Kobe University Graduate School of Medicine reported that sulfonylureas may stimulate insulin secretion through an additional mechanism-direct activation of rap guanine nucleotide exchange factor 4 (RAPGEF4; EPAC2).

Using imaging studies in mouse pancreatic $\beta$ cells, the team showed that the generic sulfonylureas tolbutamide and glibenclamide agonized Epac2, which in turn activated RAP1 GTPase activating protein (RAPGAP; RAP1) and stimulated insulin secretion.

In wild-type and $\mathrm{Epac2}^{-{ }_{-}}$mouse pancreatic islets, the presence of glucose or potassium produced similar increases in insulin secretion. However, insulin secretion stimulated by tolbutamide or glibenclamide was lower in the knockout cells than in the wild-type cells, suggesting that Epac2 activation is necessary for sulfonylureas to stimulate insulin secretion.

The group saw similar effects in mice. They also tested other sulfonylureas in vitro to support the more detailed results presented for tolbutamide and glibenclamide, as well as two compounds closely related to sulfonylureas, to show that the specific sulfonylurea core structure is necessary for EPAC2 binding.

The group suggested that compounds that specifically act on EPAC2 without affecting the $\mathrm{K}_{\mathrm{ATP}}$ channel could be used to treat diabetes without causing hypoglycemia.

Team leader Susumu Seino told SciBX that the next step will be to identify the sulfonylurea binding site on EPAC2 and to develop agonists of the protein. Seino is a professor in the Division of Biomedical Sciences at the medical school.

Purdue's Hockerman agreed. "The key for utilizing EPAC2 directly as a drug target will be to develop new pharmacophores that can activate EPAC2 but not $\mathrm{K}_{\mathrm{ATP}}$ channels," he said. "Such a compound could potentiate glucose-stimulated insulin secretion and not chronically stimulate insulin release."

Seino did caution that a direct EPAC2 modulator could have more off-target effects than marketed sulfonylureas. Because the sulfonylureas studied in the paper bind to EPAC2, they may have extra-pancreatic effects through RAP1, which is widely expressed in tissues, he told SciBX. "And we still don't know how RAP1 affects cellular functioning in different tissues."

\section{EPAC's other actors}

Hockerman also noted that the sulfonylureas produced only modestly different effects in wild-type and Epac2-deficient mice, suggesting that activating EPAC2-at least to the extent that existing sulfonylureas activate the protein - might have only limited efficacy.

Although the specific activation of EPAC2 might not be causing a large effect on insulin secretion relative to $K_{A T P}$ inhibition, it does not mean that new analogs should not be pursued, because of the potential benefits that could be gained.

Holger Rehmann, assistant professor in the Department of Physiological Chemistry at University Medical Center Utrecht, told SciBX that he would like a better definition of the extent to which each target contributes to the beneficial effects of the sulfonylurea drugs. He said that a drug that efficiently and selectively activates EPAC2 could be used in combination with the classical drugs. This could boost the insulin-secreting potential without increasing the risk for hypoglycemia.

The more interesting question may be how such sulfonylurea analogs would compare with incretin agonists, a class of molecules that acts upstream of EPAC2 and already includes drugs on the market.

Incretins are a family of gut-secreted hormones that potentiate insulin secretion in a glucose-dependent manner and avoid hypoglycemia. The hormones, such as glucagon-like peptide-1 (GLP-1), are released as glucose levels rise after a meal. GLP-1 increases intracellular adenosine $3^{\prime}, 5^{\prime}$-monophosphate (cAMP) and stimulates insulin secretion in the pancreas through activation of EPAC2 and a protein kinase A (PKA)-dependent pathway. ${ }^{2}$

GLP-1 receptor agonists approved for diabetes include Byetta exenatide from Amylin Pharmaceuticals Inc. and Eli Lilly and Co. and the GLP-1 analog Victoza liraglutide, which is marketed by Novo 


\section{TARGETS \& MECHANISMS}

Nordisk A/S in several European countries.

Because EPAC2 is a downstream effector of incretins such as GLP-1 and glucose-dependent insulinotropic polypeptide (GIP), Hockerman questioned whether EPAC2 agonists would be as effective as GLP-1 receptor modulators. "Incretins, such as GLP-1 and GIP, have many therapeutic effects that may or may not involve activation of EPAC2," he noted.

Seino told SciBX that a patent application has been filed covering the work in the Science paper.

Martz, L. SciBX 2(32); doi:10.1038/scibx.2009.1233

Published online Aug. 20, 2009

\section{REFERENCES}

1. Zhang, C. et al. Science; published online July 30, 2009; doi:10.1126/science. 1172256

Contact: Susumu Seino, Core Research for Evolution Science and Technology, Tokyo, Japan e-mail: seino@med.kobe-u.ac.jp

2. Holz, G. Diabetes 53, 5-13 (2004)

COMPANIES AND INSTITUTIONS MENTIONED

Amylin Pharmaceuticals Inc. (NASDAQ:AMLN), San Diego, Calif. Eli Lilly and Co. (NYSE:LLY), Indianapolis, Ind.

Kobe University Graduate School of Medicine, Kobe, Japan Novo Nordisk A/S (CSE:NVO; NYSE:NVO), Bagsvaerd, Denmark Purdue University, West Lafayette, Ind.

University Medical Center Utrecht, Utrecht, the Netherlands 